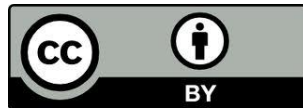

\title{
RELIGIOSIDADE CLÁSSICA, ESPIRITUALIDADE CONTEMPORÂNEA E QUALIDADE DE VIDA: DISCUSSÕES PSICOLÓGICAS
}

\author{
Classic Religiousness, Contemporary Spirituality and Quality of Life: A Psychological Discussion
}

\author{
Geraldo José de Paiva \\ Universidade de São Paulo \\ Professor titular do Instituto de Psicologia da USP \\ Vice-Coordenador do GT Psicologia \& Religião, da ANPEPP
}

\begin{abstract}
RESUMO: Definem-se os conceitos de religiosidade, espiritualidade e qualidade de vida e discutem-se algumas relações entre qualidade de vida e, de um lado, religiosidade e, de outro, espiritualidade. As referências psicológicas utilizadas nessa discussão incluem emoção, corporalidade, identidade, pertença grupal e fatores de personalidade. Na comparação, lastreada em estudos experimentais da literatura psicológica, religiosidade e espiritualidade revelam modalidades ou gradações diferentes nessas variáveis psicológicas, dependentes da cultura e da faixa etária dos sujeitos e da maneira como lhes são propostos os quesitos no instrumento. Apontam-se as contribuições que religiosidade e espiritualidade podem oferecer para a qualidade de vida.
\end{abstract}

Palavras chave: Religiosidade; Espiritualidade; Qualidade de vida; Psicologia da religião.

ABSTRACT: Religiosity, Spirituality and Quality of Life are conceptually defined and some of their relationships are discussed. Leading psychological references guiding this dicussion are emotion, corporality, identity, group belonging, and factors of personality. Their comparison, based on experimental research from psychological literature, demonstrates how spirituality and religiosity acquire different modalities or degrees in these psychological variables, according to the culture and age of the subjects and to the manner of presentation of the questions in the instrument. The contribution of Religiosity and Spirituality to Quality of Life are pointed out.

Keywords: Religiosity; Spirituality; Religiosity; Quality of life; Psychology of religion. 
Três termos são importantes para a discussão psicológica da relação entre Espiritualidade e Qualidade de Vida: espiritualidade, qualidade de vida e, como comparação, religiosidade.

A discussão dirá respeito à psicologia, a saber, àquela faixa intermediária entre o lógico e o biológico, em que se dão os processos tipicamente denominados psíquicos, de que são exemplo as cognições sociais, as disposições emocionais, os trabalhos da imaginação e os desejos. O tratamento dos termos e de suas relações sob o enfoque da psicologia apoia-se principalmente em estudos do Centro de Psicologia da Religião da Universidade Católica de Louvain (Louvain-la-Neuve), coordenados por Vassilis Saroglou, diretor daquele Centro. A escolha desses estudos se deve à comparação que estabelecem freqüentemente entre os resultados obtidos em amostras européias e amostras norte-americanas. Se a temática parecer de interesse para a pesquisa acadêmica brasileira, como aparentemente o é (Paiva, 2004; 2005 a, b; Paiva \& Fernandes, 2006), essa comparação poderá sugerir projetos de investigação em nosso meio.

\section{Espiritualidade}

Espiritualidade é um termo originário do Novo Testamento, derivado do neologismo latino spiritualis (pneumatikós), que designava o campo do ensinamento sapiencial da Bíblia (Sudbrack, 1993). A palavra encontra, pois, seu nicho na tradição religiosa cristã mais antiga e principalmente na tradição católica. Lembrem-se as espiritualidades franciscana, carmelita, dominicana, jesuítica, luterana, calvinista, jansenista e outras (Paiva, 2004). A riqueza dessa tradição pode ser vista, por exemplo, nos dezessete volumes de M.Viller e colaboradores, Dictionnaire de Spiritualité ascétique et mystique (1932-1995).

Tornou-se, contudo, hoje um conceito polissêmico (Saroglou, 2003), impreciso (Zinnbauer et al., 1997), sutil e evanescente (Paiva, 2004), "um conceito em busca de seu significado" (Westerink, 2012), relacionado ora com o Espírito Santo, ora com o espírito iluminista, ora com o espírito humano imbuído de intuição e afetividade (Rican, 2003; 2004). É um termo de uso corrente, portador de uma inteligibilidade largamente compartilhada porque carregada de conotações e denotações aparentadas, embora não unívocas. Alguns estudiosos dos movimentos culturais do Ocidente (Falque, 2001; 
Vergote, 2003; Saroglou, 2003) atribuem o interesse pela espiritualidade a mudanças culturais que se verificam na modernidade tardia ou na pós-modernidade, embora divirjam em atribuí-lo à experiência da secularização. $\mathrm{O}$ que parece ressaltar dessas mudanças é a tendência a recuperar a amplitude do espírito humano e o sentido de integração ou totalidade. Nestes últimos séculos, com efeito, o espírito ocidental foi entendido principalmente como razão analítica, que deu origem às ciências e às técnicas, com o que implicam de segmentação não só do conhecimento, mas das esferas de vida, e de negação das diferenças. Observa-se hoje a tentativa de correção desse excesso, com a valorização da emoção, da imaginação, da intuição e da conexão com o universo (connectedness). A compensação pendular dos excessos da razão volta-se, com freqüência, para expressões ligadas ao concreto, ao material, ao corporal, paradoxalmente vividas como forma de espiritualidade. Paradoxalmente, porque o concreto, o material e o corporal desprendem-se, por assim dizer, das restrições do aquie-agora e do imediato, que caracterizam a materialidade (Paiva, 2005b). Esse paradoxo do material vivido como espiritual é resolvido com diversas soluções, umas mais felizes do que outras. Registram-se, assim, variadíssimas modalidades de espiritualidade, tributárias inclusive de tradições orientais, africanas e indígenas, tornadas disponíveis, por um novo paradoxo, pelas facilidades do mercado que, sob outro ponto de vista, é por vezes rejeitado como expoente da razão instrumental capitalista. Ioga, meditação transcendental, práticas zen, tarô, I-Ching, alinhamento dos chacras, tai-chi-chuan, são algumas dessas modalidades buscadas nas tradições do hinduísmo e do budismo. Cultos afros (Leite, 1996) e celtas (Barker, 1995), druidismo, religião do vegetal (Landim, 1990), xamanismo, cultivo de duendes e gnomos, vibrações cósmicas e energias, por meio de pedras, árvores, ervas, cristais, cores e pirâmides, contatos extraterrestres, inclusive mediados por discos voadores, harmonias inusitadas como a world, ethnic ou new wave music, experiências de quase-morte, são outros tantos recursos para os que Wade Clark Roof (1993), sociólogo da religião, pioneiramente caracterizava como os seekers $_{2}$ os que andam em busca de um novo sentido integrador para a vida (Paiva, 2004). Não é de admirar que diante dessa multiplicidade de manifestações, já se tenha falado do outro da razão, isto é, da abdicação da razão clássica, que opera no rigor dos conceitos e da articulação dos juízos, em favor de outros modos de conhecimento, tachados de irracionais, encontrados até em filósofos e pensadores contemporâneos 
(Habermas \& Ratzinger, 2004). Registre-se, contudo, que filósofos como Robert C. Solomon (2003), da Universidade do Texas, reconhecem à espiritualidade uma racionalidade, embora não do tipo hiper-racional geralmente atribuída ao conhecimento científico. Ainda assim, como sugere a referência aos seekers, a espiritualidade busca alguma coisa. Qual o objeto dessa busca? Na interpretação de um scholar perito em psicologia e teologia, o recentemente falecido professor Antoine Vergote, da Universidade de Leuven, essa busca tem como objeto um divino difuso, que se encontra na natureza e no cosmos. No entendimento de Vergote (2003), o Ocidente, em geral, e mais em particular a Europa, estão cansados da palavra "deus" e de sua vulgata teológica. A busca empreendida pela espiritualidade, exprime "o desejo de atingir uma liberdade interior e de encontrar para a vida um sentido que liberta do racionalismo estreito e das concepções tristemente utilitárias" (Vergote, 2003: 98). Mais especificamente, a espiritualidade preocupa-se com a dimensão da existência referida a "o divino ou o mistério sagrado que a pessoa percebe afetiva e intuitivamente na natureza, no nascimento de um ser humano, na arte e no amor" (Vergote, 2003: 97). Essa seria, do ponto de vista da teologia e da história das religiões, uma posição précristã, apropriada a uma religião da natureza não politeísta, um ateísmo, segundo Vergote (2003), não irreligioso. As considerações até agora apresentadas tentam circunscrever o fenômeno da espiritualidade como algo atual, multivariado, desamarrado da racionalidade instrumental. Resta aproximar esse fenômeno do enfoque da psicologia. Saroglou (2003) realiza essa aproximação sob dois ângulos: o da fenomenologia, isto é, da percepção que têm da espiritualidade os que se dizem espirituais, e o da linha-mestra da psicologia, que procura, na espiritualidade, variáveis, entre outras, de ordem cognitiva, afetiva, psicossocial e da personalidade. Saroglou empreende essa procura de forma comparativa, isto é, comparando essas variáveis na espiritualidade e na religiosidade clássica. Antes de reportar os resultados dessa comparação, é interessante antecipar alguns achados da pesquisa norte-americana do tema, com o fim de esclarecer a natureza da espiritualidade, do ponto de vista da psicologia. A conceituação de religião e espiritualidade e a medição desses constructos vem ocupando a psicologia norte-americana da religião há mais de duas décadas. Momento catalisador desse interesse foi o trabalho de Roof (1993), A_generation of seekers, que destacou na geração dos chamados $\underline{\text { baby }} \underline{\text { boomers, }}$ então com seus trinta e 
poucos anos, um percentual que não professava nenhuma adesão a tradições e grupos religiosos, mas se mostrava em jornada de busca espiritual. Iniciava-se, então, a oposição entre religião e espiritualidade, grosso modo relacionada com crenças e práticas institucionalizadas ou com liberdade e criatividade na composição do que se crê e se pratica fora do estabelecido por uma instituição. E essa oposição se prolongou, naturalmente, em conotações valorativas de bem e mal, segundo a ideologia dos avaliadores. Alguns estudos mostraram até que as pessoas passaram a declarar-se espirituais e não religiosas (Pargament, 1999; Rican, 2003; Paiva, 2005a). Estudos posteriores, de Zinnbauer e colaboradores (1997), e do próprio Roof (2000), mostraram, contudo que, quando oferecida a alternativa de se declararem religiosas $e$ espirituais, a grande maioria das pessoas se dizia religiosa $e$ espiritual, e reconhecia interdependência entre espiritualidade e religiosidade (Marler \& Hadaway, 2002). Marler \& Hadaway (2002) verificaram, contudo, que a coorte etária mais jovem tende a abandonar o religioso e a encaminhar-se para o espiritual. Observam, entretanto, que quando a opção é exclusivamente pelo espiritual isso se obtém às expensas do religioso ou, em suas palavras, a pessoa menos religiosa não se torna mais espiritual. Quanto ao que os entrevistados dos vários levantamentos entendem por religiosidade e espiritualidade, apurou-se, um tanto dependentemente da posição funcional dos teóricos que conduziram as pesquisas (Paiva, 2003), que, apesar da diversidade de expressões, manifestou-se um núcleo homogêneo relativo ao sagrado: Deus, Cristo, a Igreja. Desses estudos conclui-se que, ao contrário do que indicam certas pesquisas mais específicas, a oposição entre cristão/religioso e espiritual nos Estados Unidos tem algo de artificial, e que a famosa afirmação "não sou religioso, mas espiritual" não tem a generalidade que lhe tem sido atribuída. Analogamente, na Europa, em particular na Escandinávia, contrasta-se o religioso com o cristão e não com o espiritual (Stifoss-Hansen, 1999; Paiva, 2005b).

\section{Qualidade de Vida}

Qualidade de vida é um termo relativamente recente, referido ao bem-estar físico e/ou mental da pessoa e, de modo geral, a sua saúde. É interessante observar que o termo se contrapõe a quantidade de vida, que não deixa de continuar um problema para várias populações. $\mathrm{O}$ interesse pela qualidade de vida, sucedeu ao interesse pela 
quantidade, a tal ponto que nos países onde a longevidade é maior se cunhou a frase: o que importa não é acrescentar anos à vida, mas vida aos anos.

Em que consiste essa qualidade de vida é tema de discussão. As definições destacam ora a plena realização dos objetivos pessoais, ora a felicidade ou satisfação, ora a utilidade e preferência sociais. A Organização Mundial da Saúde define qualidade de vida como a percepção que as pessoas têm de sua posição na vida, no contexto dos sistemas culturais e de valores nos quais vivem e em relação a seus objetivos, expectativas, padrões e interesses. Qualidade de vida envolve, pois, um certo número de recursos disponíveis em termos individuais, físicos e psíquicos, em termos sociais e alguns pensam também em termos de alguma forma transcendentais ao indivíduo e ao grupo, isto é, em termos espirituais ou religiosos. A sensibilidade da área profissional da psiquiatria por essa dimensão do bem-estar da pessoa, justificou a inclusão, entre os distúrbios psicopatológicos do DSM IV, dos problemas espirituais e religiosos (Turner, Lukoff, Barnhouse \& Lu, 1995). A relação com algum tipo de transcendência, que vá além do indivíduo, ou do grupo, ou do tempo/espaço presente, é capaz, com efeito, de conectar a pessoa com totalidades abrangentes, no interior das quais as vicissitudes pessoais ou grupais, temporais ou espaciais, adquirem uma posição mais descentrada. Essa relação pode ser estabelecida por via das religiões que, em geral, apontam um pólo sobre-humano de referência, geralmente de natureza pessoal, ou por via das espiritualidades, sejam elas tributárias de fontes religiosas ou de fontes naturais. Ressalte-se que, mesmo no último caso, vários estudiosos apontam o sagrado como o definidor da espiritualidade, não bastando a intensidade do comprometimento ou a dignidade do objeto e da atividade considerados (Pargament, 1997; Hill, Pargament, Hood, Jr., Mccullough, Swyers, Larson \& Zinnbauer, 2000). Naturalmente, no estabelecimento do alvo da qualidade de vida se observam muitas posições teóricas e analíticas. Chega-se a pensar que, no lugar da virtude, proposta desde a Antigüidade por Aristóteles como definidora da "vida boa", acolha-se um novo padrão, o da qualidade de vida. A saúde, entendida como boas condições de vida física e psíquica, passa a ser objeto da política, que se denomina biopolítica da saúde. Em consequiência, a própria identidade passa a denominar-se bio-identidade e o mundo humano é substituído pelo mundo ecológico (Freire Costa, 2005). Segundo Jurandir Freire Costa, a bioidentidade é garantida pela bio-ascese, e "a fitness é a suprema virtude." Essa tendência, 
para a qual já advertia o Encontro "Espiritualidade e Qualidade de Vida", de Porto Alegre (Teixeira, Muller \& Silva, 2004; Paiva, 2004), traz o perigo de ordenar ao bemestar físico e psíquico a existência da pessoa, deixando de lado, de maneira irrealista, o sofrimento -e a compaixão- que só numa dimensão espiritual ou religiosa não subordinada a outros interesses pode ser admitido como integrante de uma dignidade humana menos egocentrada. Nesse ponto recorde-se o diálogo, mantido, em 1995, entre Umberto Eco e o cardeal Carlo Maria Martini, de Milão, e reproduzido nas cartas que um e outro se trocaram no livro Em que crêem os que não crêem? (Eco \& Martini, 1999). Como muitos hoje em dia, e certamente com muita razão, Umberto Eco propunha a vida, sua proteção e seu desenvolvimento, como o sentido último do empenho humano, individual e social. A essa proposta o cardeal Martini observava que a palavra "vida", nos textos gregos das Escrituras do judaísmo e do cristianismo, encontra-se na forma de dois vocábulos: $\underline{\text { bíos }}$ e zoé. Bíos é a vida natural, zoé é a vida divina partilhada pelo ser humano. Não há simples oposição entre os dois sentidos, mas a palavra zoé acrescenta uma denotação singular. Talvez por isso, entre os santos cristãos não se encontra nenhum chamado Bíos, embora haja um Políbio, mas encontram-se várias santas com o nome de Zoé. É claro que o sentido de zoé foi particularizado na tradição bíblica e não na linguagem profana, que fala tanto de biologia como de zoologia, e correlatos, sempre no sentido de uma vida situada na imanência da experiência do animado versus o inanimado. A discussão Eco/Martini nos desperta, no entanto, para a necessidade da reflexão acerca do que é a qualidade de vida e da virtualidade que essa expressão carrega. Essa re-orientação fornecida pelos dois eminentes intelectuais recoloca numa direção mais conforme à própria tradição ocidental, da vida virtuosa, e impede reduzir à longevidade, à ausência do sofrimento, à realização do potencial biológico, numa palavra ao que Freire Costa (2005) denomina bio-identidade, aquilo que tanto a religiosidade como a espiritualidade almejam como uma vida digna de ser vivida ou o que Solomon (2003: 18) denomina "um amor solícito e atencioso [thoughtful] ì̀ vida."

\section{Religiosidade}

Em precioso estudo acerca da "espiritualidade moderna do ponto de vista da psicologia da religião", Vassilis Saroglou, da Universidade de Louvain-la-Neuve, 
examina as diferenças psicológicas induzidas nas pessoas pela religião e pela espiritualidade (Saroglou, 2003). Saroglou ressalva, desde o início, que é a psicologia anglo-saxã que se vê como que encantada com os estudos empíricos sobre a importância da espiritualidade para a saúde e o bem-estar da pessoa e com o desenvolvimento de medidas de espiritualidade. A pesquisa do autor privilegia os estudos europeus, comparando-os, quando possível, com os norte-americanos. Reconhecendo, como em geral se faz, que é espinhosa a distinção entre o espiritual e o religioso, Saroglou define como religioso o quadro sócio-ideológico caracterizado por cinco componentes essenciais: rito, comunidade, regras éticas específicas, doutrinas e crenças, aspectos emocionais; como espiritual, caracteriza a tendência de vários contemporâneos a interessar-se, deixar-se atrair e realizar investimentos pessoais em aspectos tradicionalmente ligados ao religioso e que hoje podem ser abordados num quadro não religioso. $\mathrm{O}$ autor levanta questões importantes para a psicologia da religião: em que a espiritualidade moderna ainda é religiosa, do ponto de vista psicológico? As teorias psicológicas clássicas da religião ainda valem para a espiritualidade moderna? Qual o perfil das pessoas atraídas para a espiritualidade: trata-se de pessoas secularizadas ou de pessoas que buscam novas formas de expressão do religioso? A espiritualidade chegaria a ser um dos fatores psicológicos da personalidade? Saroglou resume em seis pontos os resultados de suas análises do comportamento de amostras belgas de língua francesa. Do ponto de vista da importância, a espiritualidade é mais popular principalmente entre os mais jovens e diz respeito à própria idéia de Deus: quase um quarto da população estudada se identifica com uma espiritualidade sem Deus e sem religião. A espiritualidade emergente atinge 50\% dos jovens estudados, e não parece uma compensação da secularização, isto é, mais se apresenta como busca de nova maneira de exprimir o religioso do que como um sucedâneo da imanentização religiosa operada pelo processo de secularização. As pessoas que se dizem espirituais incluem na espiritualidade algumas dimensões: autonomia da pessoa face à tradição e às instituições, busca pessoal de sentido, conexão com a totalidade; aceitação de um princípio transcendente ao indivíduo e a este mundo, ênfase no aspecto experiencial, em contraposição ao demasiado cognitivo das doutrinas, mal-estar em relação à materialidade do mundo. Como busca de sentido, a espiritualidade emergente e a religiosidade clássica, ao contrário de abordagens filosóficas e existenciais, acreditam 
na existência de um sentido e de uma finalidade da vida individual e do mundo. As duas modalidades se diferenciam, no entanto, quanto à motivação cognitiva de ordem, estruturação e fechamento na construção do sentido, ausente na espiritualidade, e quanto à facilidade de oferecer respostas aos enigmas da existência, presente na religião. As motivações afetivas não distinguem espiritualidade e religião, enquanto nem uma nem outra implicam instabilidade emocional. A espiritualidade parece independente do papel compensador da religião nos conflitos conjugais, mas por não implicar forte laço com a comunidade, não oferece o apoio social que a religião confere à saúde física e mental. $\mathrm{Na}$ espiritualidade percebe-se um passado ou um presente problemáticos na história do apego, com práticas ligadas a leituras voltadas para a Nova Era, para o paranormal e a astrologia. Como a religião, a espiritualidade aprece nos momentos de crise e de adversidade. Em relação aos traços de personalidade, observou-se na espiritualidade a presença da atitude pró-social e altruísta, mas menos forte do que na religião clássica. $\mathrm{O}$ espírito consciencioso e a rigidez de idéias e valores, associados aos chamados Big $F i v e^{\mathrm{ii}}$, estão ausentes da espiritualidade, a qual se distingue pela extroversão (interesse por atividades sociais por pessoas) e pela abertura à experiência, em sua multiplicidade, variedade e novidade, que inclui as experiências paranormais. Finalmente, no que tange aos valores, espiritualidade e religião coincidem no cuidado com o outro e com o respeito do outro na expansão do eu. Coincidem também no anti-hedonismo, embora mais fraco na espiritualidade. Mais amplamente que a religião clássica, a espiritualidade sai do ingroup para o universalismo das identidades coletivas, da justiça social, da ecologia e da definição de quem é o próximo. Os resultados analisados por Saroglou (2003) coincidem com os discutidos pelos pesquisadores norte-americanos quando, indo além da representação conceitual, se buscam variáveis concretas do comportamento. A representação conceitual tende a distinguir e a opor espiritualidade e religião; a prática comportamental, no entanto, assume muito da religiosidade na espiritualidade, e viceversa. Dessa forma, Saroglou (2003) propõe que, mais do que oposição, encontra-se gradação entre uma atitude e outra. Embora se possa admitir que a revelação foi dada de uma vez por todas, como se diz do cristianismo (Judas, 3), a religião é parte da cultura, transforma-se com a cultura e contribui para sua transformação. A sensibilidade ocidental contemporânea, que ainda perlabora as grandes e profundas alterações filosóficas, políticas, sociais, econômicas e outras, que a atingiram no último século, 
busca, naturalmente, novas expressões, quando não novos sentidos, para a existência do homem e do cosmos. Muito de novo pode ser tirado do velho tesouro das religiões clássicas, como o demonstra um sem-número de iniciativas que restauram, inclusive, espiritualidades clássicas. Mas é possível, como mais de uma vez observa Vergote (2003), que as formulações antigas não correspondam mais à nova sensibilidade cultural. Nesse caso, as espiritualidades são tentativas, as mais das vezes bastante individuais e transitórias, de se expressar o estar-no-mundo das pessoas. Como vimos, no entanto, os dados sugerem que essas tentativas se movem no interior dos parâmetros das religiões. Como não se trata de atitudes estanques e opostas, a busca espiritual pode contribuir para a oxigenação da religião clássica. Um exemplo interessante e desafiador é o relacionado com a identidade psicossocial. Talvez até a psicologia evolucionária estabeleça que o in-group e o out-group sejam configurações pré-conceituais necessárias para a cognição e a construção da identidade. E nesse ponto as religiões clássicas têm mostrado, na teoria e na prática, como funcionam o_in-group e o outgroup. Nesse momento poder-se-ia descobrir uma oposição entre a identidade particular e a identidade coletiva ou universal. No entanto, essas mesmas religiões contêm elementos e energias que apontam para a superação do in-groups_muito estreitos (judeu e grego, homem e mulher, escravo e livre) em direção a agrupamentos com limites muito mais dilatados ou, até, sem limites. A espiritualidade, que tende a uma ecologia universal, pode ajudar a religião a reencontrar alguma de suas inspirações mais profundas e mais difíceis.

Pode-se, pois, pensar que a religião (clássica) e a espiritualidade (contemporânea) contribuem para a qualidade de vida num sentido corretivo e num sentido de fomento. A religião e a espiritualidade correm o risco de se tornarem instrumentais em relação ao ego da pessoa, ao que hoje se denomina bio-identidade, isto é, a identidade centrada na vida do corpo ou na pessoa em sua constituição corporal. Gordon Allport (1950), já na década de 50, iniciava a discussão da possibilidade de instrumentalização da religião, ao distinguir a religião extrínseca da religião intrínseca. Na primeira hipótese, religião e espiritualidade estariam subordinadas à qualidade de vida. Porém tanto a religião como a espiritualidade podem sobrepor-se a objetivos essencialmente redutores e reduzidos e abarcar a totalidade, a universalidade, cuja clef de voûte é alguma forma de transcendência. Nessa outra hipótese, religião e 
espiritualidade estariam contribuindo positivamente para a qualidade de vida. Algumas dessas contribuições foram apontadas nos estudos empíricos de V. Saroglou (2003): um certo apofatismo libertador, novas formas de expressão religiosa, autonomia responsável, conexão com o todo, percepção da transcendência, valorização das emoções, desconforto com o materialismo, revalorização da busca do sentido da vida, altruísmo pró-social, diminuição do legalismo, abertura à variedade das experiências, ampliação dos limites grupais e extensão do conceito de "próximo". Como vimos, Saroglou (2003), da mesma forma que diversos pesquisadores norte-americanos, descobre bastante sobreposição entre espiritualidade e religião ao longo dessas características. Se qualidade de vida for entendida no mínimo como o "amor solícito e atencioso à vida", de que fala Solomon (2003: 18), essa sobreposição fomentará essa qualidade, respeitando a dinâmica da pessoa, dos grupos e das culturas.

\section{Referenciais}

Allport, G.W. (1950). The individual and his religion. Nova York: Macmillan American Psychiatric Association (1994). Diagnostic and statistical manual of mental_disorders ( $4^{\text {th }}$ ed.). Washington, DC.

Barker, E. (1995). The New Age in Britain. Em J.-B.Martin \& F. Laplantine (Orgs.), Le défi magique. Esotérisme, Occultisme, Spiritisme. (Vol. 1, 327-337) Lyon: Presses Universitaires de Lyon..

Eco, U. \& Martini, C. M. (1999). Em que crêem os que não crêem?_(Tradução de Eliana Aguiar). Rio de Janeiro: Record.

Falque, E. (2001). Mystique et modernité. Aspirations spirituelles de notre temps et mystique chrétienne. Etudes, Juin, n. 3946, 785-792.

Freire-Costa,J.(2005).A subjetividade exterior. www.jfreirecosta.com/subjetividade.html

Godin, A. (1962). Santé mentale et vie chrétienne. Importance et complexité des recherches scientifiques. Archiv fürReligionspsychologie, 7, 224-237.

Goldberg, L. R. (1990). An alternative description of personality: The big-five factor structure. Journal of Personality and Social Psychology, 59, 1216-1229.

Habermas, J. \& Ratzinger, J. (2004). Pluralisme et Morale. Esprit, n. 306, 6-28.

Hill, P.C., Pargament, K. I., Hood, Jr., R. W., Mccullough, M. E., Swyers, J. P., Larson,

D.B. \& Zinnbauer, B. J. (2000). Conceptualizing religion and spirituality: points of commonality, points of departure. Journal for the Theory of Social Behaviour, 30 (1), $51-77$. 
Landim, L. (1990), (Org.). Sinais dos Tempos. Diversidade religiosa no Brasil. Rio de Janeiro: ISER.

Leite , I. de A (1996). A Oração dos Doutores. Um estudo sobre a religiosidade dos intelectuais. Dissertação de Mestrado. São Paulo: FFLCH da Universidade de São Paulo.

MacDonald, D.A (2000). Spirituality: Description, Measurement and Relation to the Five Factor Model of Personality. Journal of Personality, 68 (1), 185-194.

Marler, P. L. \& Hadaway, C. K. (2002). "Being religious" or "being spiritual" in America: a zero-sum proposition? Journal for the Scientific Study of Religion, 41 (2), 289-300.

McCrae, R.R. \& John, O.P. (1992). An introduction to the Five-Factor Model and its applications. Journal of Personality, 57, 415-433.

Paiva, G. J. de (2003). Enfrentamento religioso da doença: uma possibilidade? Em M. H.de Freitas (Org.), Saúde e Religião. Brasília: Universa, 11-20.

Paiva, G. J.de (2004). Espiritualidade e qualidade de vida: pesquisas em psicologia. Em E.F.B.Teixeira, M.C.Muller e J.D.T.da Silva (Orgs.). Espiritualidade e Qualidade de Vida. Porto Alegre: Edipucrs, 119-130.

Paiva, G. J.de (2005a). Psicologia da religião, Psicologia da espiritualidade: oscilações conceituais de uma (?) disciplina._Em M. M. Amatuzzi (Org.). Psicologia da Religião e da Espiritualidade. São Paulo: Paulus, 31-47.

Paiva, G.J. de (2005b). Psicologia da Espiritualidade/Espiritualidade da Psicologia. Magis, Cadernos de Fé e Cultura, Centro Loyola de Fé e Cultura, n.47 (julho), 9-20.

Paiva, G. J. de \& Fernandes, M. I. A. (2006). Espiritualidade e saúde: um enfoque da psicologia. Em E. M. Vasconcelos (Org.). A espiritualidade no trabalho em saúde. São Paulo: Hucitec, 186-197.

Pargament, K. I. (1997). The psychology of religion and coping. Theory, research, practice. Nova York: The Guilford Press.

Pargament, K. I. (1999). The psychology of religion and spirituality? Yes and No. The International Journal for the Psychology of Religion, 9, 3-16.

Piedmont, R. L. (1999). Does spirituality represent the sixth factor of personality? Spiritual Transcendence and the Five-Factor Model. Journal of Personality, 67_6), 9851013.

Rican, P.R. (2003). Spirituality - a story of a concept._Comunicação na International Psychology of Religion Conference. Glasgow, Escócia Rican, P.R. (2004). Spirituality: The story of a concept in the Psychology of Religion. Archive for the Psychology of Religion, 26, 135-156

Roof, W. C. (1993). A generation of seekers: The spiritual journey of the baby boom generation._San Francisco: Harper. Saroglou, V. (2003). Spiritualité moderne: un regard de psychologie de la religion. Revue_Théologique de Louvain, 34(4), 473-504. 
Solomon, R. C. (2003). Espiritualidade para céticos. Paixão, Verdade cósmica e Racionalidade no século XXI (Tradução de Maria Luisa X. de A. Borges). Rio de Janeiro: Civilização Brasileira (orig. 2002).

Stifoss-Hansen, H. (1999). Religion and spirituality: What an European ear hears. The

International Journal for the Psychology of Religion, 9, 25-33.

Sudbrack, J. (1993). Spiritualité. Em P.Dinzelbacher, Dictionnaire de la Mystique. Paris: Brepols, 716-7

Teixeira, E.F.B., Muller, M.C. \& Silva, J.D.T. (Orgs.) (2004). Espiritualidade $e$ Qualidade de Vida. Porto Alegre: Edipucrs,

Turner, R.P., Lukoff, D, Barnhouse, R.T. \& Lu, F. G. (1995). Religious or spiritual problem: A culturally sensitive diagnostic category in the DSM-IV. Journal of Nervous and Mental Disease, 183, 435-444.

Vergote, A (2003). La théologie devant les changements culturels en Europe. Em G. H. Pesch \& J.-M. van Cangh (Orgs). Comment faire de la théologie aujourd'hui? Continuité et renouveau. (pp. 95-117). Paris: Cerf.

Viller, M., Derville, A., Lamarche, P. \& Solignac, A. (1932-1995). Dictionnaire de Spiritualité ascétique et mystique: doctrine et histoire. Paris: Beauchesne, 17 vols.

Westerinck, H. (2012). Spirutality in Psychology of Religion: A concept in search of its meaning. Archive for the Psychology of Religion, 34,1-15

Zinnbauer, B.J., Pargament, K. I \& Scott, A. B. (1999). The emerging meanings of religiousness and spirituality: problems and prospects. Journal of Personality, 67, 889919.

Zinnbauer, B. J., Pargament, K. I., Cole, B., Rye, M. S., Butter, E. M., Belavich, T. G., Hipp, K. M., Scott, A. B. \& Kadar, J. L., (1997). Religion and spirituality. Unfuzzying the fuzzy. Journal for the Scientific Study of Religion, 36, 549-564.

Notas

${ }^{1}$ Propõe-se essa paráfrase à tradução brasileira bem pensado, para manter as denotações de thoughtful.

1 Os cinco grandes (big five) fatores de personalidade são os seguintes: neuroticismo, extroversão, amabilidade, conscienciosidade e abertura à experiência (Goldberg, 1990; McRae \& John, 1992). Piedmont (1999) julga a espiritualidade, ou a transcendência espiritual, um sexto fator, caracterizado por conexão, universalidade e alegria resultante do encontro pessoal com uma realidade transcendente (prayer fulfillment).

Recebido: 01/04/2014

Received: 04/01/2014

Aprovado: $30 / 06 / 2014$

Approved: 06/30/2014 